\title{
High expression of citron kinase predicts poor prognosis of prostate cancer
}

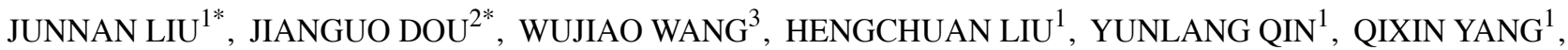

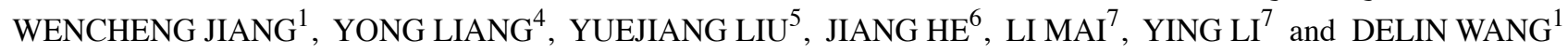 \\ ${ }^{1}$ Department of Urology, The First Affiliated Hospital of Chongqing Medical University; ${ }^{2}$ Department of Urology, \\ The People's Hospital of Dazu; ${ }^{3}$ First Clinical Institute, Chongqing Medical University, Chongqing 400016; \\ ${ }^{4}$ Department of Urology, The Zigong No. 4 People's Hospital; ${ }^{5}$ Department of Urology, The Zigong No. 1 People's Hospital, \\ Zigong, Sichuan 643000; ${ }^{6}$ Gastroenterology and Neurology Center, University-Town Hospital of Chongqing \\ Medical University; ${ }^{7}$ College of Life Science, Chongqing Medical University, Chongqing 400016, P.R. China
}

Received January 14, 2019; Accepted July 11, 2019

DOI: $10.3892 / \mathrm{ol} .2020 .11254$

\begin{abstract}
Citron kinase (CIT) is a Rho-effector protein kinase that is associated with several types of cancer. However, the role of CIT in prostate cancer (PCa) is unclear. The current study utilized microarray data obtained from The Cancer Genome Atlas, which was analyzed via Biometric Research Program array tools. Additionally, reverse transcription-quantitative (RT-q)PCR was performed to compare the mRNA expression of CIT in $\mathrm{PCa}$ tissue and in benign prostatic hyperplasia. The protein expression of CIT was detected in a consecutive cohort via immunochemistry and CIT was screened as a potential oncogene in PCa. The results of RT-qPCR demonstrated that the mRNA expression of CIT was increased in PCa tissues. Furthermore, immunochemistry revealed that CIT protein expression was positively associated with age at diagnosis, Gleason grade, serum PSA, clinical T stage, risk group, lymph node invasion and metastasis. When compared with the low expression group, patients with a high CIT expression exhibited shorter survival rates, cancer specific mortalities (CSM) and biochemical recurrence (BCR). In addition, multivariate analysis revealed that CIT was a potential predictor of CSM and $\mathrm{BCR}$. The results revealed that CIT is overexpressed during the malignant progression of $\mathrm{PCa}$ and may be a predictor of a poor patient prognosis.
\end{abstract}

Correspondence to: Dr Delin Wang, Department of Urology, The First Affiliated Hospital of Chongqing Medical University, 1 Yixueyuan Road, Chongqing 400016, P.R. China

E-mail: dlwangws@sina.com

*Contributed equally

Abbreviations: $\mathrm{PCa}$, prostate cancer; $\mathrm{BPH}$, benign prostatic hyperplasia; CIT, citron kinase; ADT, androgen deprivation therapy; PR, prostatectomy; PSA, prostate specific antigen; CSM, cancer specific morality; BCR, biochemical recurrence

Key words: prostate cancer, citron kinase, prognosis

\section{Introduction}

Prostate cancer (PCa) is one of the most common cancers worldwide (1), with an incidence rate that has increased in China in recent years (2). Prostate specific antigen (PSA) screening is a primary method for the surveillance of $\mathrm{PCa}$. However, PSA exhibits a low specificity, which leads to the incorrect diagnoses and treatment of patients with PCa (3). Therefore, the discovery and identification of new biomarkers are essential for monitoring patients with $\mathrm{PCa}$.

Citron-kinase (CIT) comprises an amino-terminal serine/threonine kinase domain, which is highly conserved between insects and mammals (4). It has been revealed that CIT is critical for cytokinesis $(5,6)$. CIT is also involved in the cleavage of the furrow and midbody, which is essential to cellular abscission (7-9). Furthermore, CIT phosphorylates the regulatory light chain of myosin II at the Ser 19/Thr 18 positions, consequently activating myosin II, which is the primary motor protein and responsible for cytokinesis (10).

In the current study, increased expression of CIT was identified as an oncogene by bioinformatic analysis. This result was verified by reverse transcription-quantitative (RT-q)PCR and immunochemistry. The aim of the current study was to assess the role of CIT in PCa and to determine the possibility of using CIT in the diagnosis and therapy of patients with PCa.

\section{Materials and methods}

Dataset gene expression analysis. mRNA expression profiles and associated PCa clinical datasets (PRAD_2015_02_24) from The Cancer Genome Atlas (TCGA) were downloaded from the University of California Santa Cruz cancer genome browser (https://xena.ucsc.edu/welcome-to-ucsc-xena/). The profile contained 52 cases of normal tissue and 499 cases of primary PCa tissue. Microarray data were normalized and compared using Biometric Research Program (BRB) array tools developed by Dr Richard Simon and Dr Yingdong Zhao (http://linus.nci.nih.gov/BRB-ArrayTools) (11). Differentially expressed genes (DEGs) were filtered by comparing cancer 
and normal tissue, Gleason grades $\geq 7$ and Gleason grades $<7$, PSA $\geq 10 \mathrm{ng} / \mathrm{ml}$ and PSA $<10 \mathrm{ng} / \mathrm{ml}$, Ta-2 and T3-4, regional lymph node metastasis (N1) and no regional lymph nodes metastasis (N0), and metastasis to distant organs (M1) and no distant metastasis (M0). DEGs were defined as a fold-change (FC) $>1$ and $\mathrm{P}<0.01$. Volcano plots were established to visualize the genes that were screened.

Patients and tissues. To determine the expression of CIT mRNA in patients with $\mathrm{PCa}$, fresh $\mathrm{PCa}$ tissue $(\mathrm{n}=35)$ and benign prostatic hyperplasia tissue $(\mathrm{BPH} ; \mathrm{n}=20)$ were collected from the First Affiliated Hospital of Chongqing Medical University (Chongqing, China). All samples were confirmed by pathological examination and subsequently stored in liquid nitrogen $\left(-196^{\circ} \mathrm{C}\right)$ for mRNA analysis. Patient characteristics are shown in Table I.

Formalin fixed paraffin embedded BPH $(n=39)$ and $\mathrm{PCa}(\mathrm{n}=271)$ samples were retrieved from the Pathology Department of the First Affiliated Hospital of Chongqing Medical University, Zigong Fourth People's Hospital and Zigong First People's Hospital from 2005 to 2017. None of the patients recruited into the present study received chemotherapy, radiation therapy androgen deprivation (ADT) or radical prostatectomy (RP) prior to enrollment. The use of tissue was approved by the Ethics committee of the First Affiliated Hospital of Chongqing Medical University (approval no. 2018-69), Zigong Fourth People's Hospital (approval no. 2018-32) and Zigong First People's Hospital (approval no. 2018-47).

Patients were sub-divided into a high-risk group (HR-group) when one of the following criteria was met: i) Gleason grades $\geq 8$; ii) T2c-T4 tumor or iii) PSA level $\geq 20 \mathrm{ng} / \mathrm{ml}$ (12). Patients that exhibited local invasion and metastasis were considered to have aggressive PCa (13). The Gleason score was evaluated according to the guidelines conducted by World Health Organization and the International Society of Urological Pathology $(14,15)$. Moreover, patients with PCa were stratified into three grades including low, middle and high grade, which determined by a Gleason sum $<5$, between 5 to 7 , and $>7$, respectively (16).

Patients who received RP were followed-up by a telephone call and patients who received ADT were monitored via continuous serum PSA surveillance (in 6-month intervals). The follow-up time of patients receiving ADT was 14.6 \pm 8.2 months with $54.2 \%$ patients being followed-up for more than one year. The follow-up time of patients receiving RP was $25 \pm 20.3$ months, with $66.3 \%$ patients being followed-up for more than one year. Due to the different therapies administered and the follow-up methods used, follow-up outcomes were stratified to cancer-specific mortality (CSM) for patients receiving $\mathrm{RP}$ and biochemical recurrence (BCR) for patients receiving ADT. BCR was defined when patients exhibited a PSA level $\geq 0.2 \mathrm{ng} / \mathrm{ml}$ on at least two consecutive postoperative occasions, as described previously (17).

Immunohistochemistry. Tissues from the patients were fixed in $10 \%$ buffered formalin at room temperature for 2 days, and then were transferred to $70 \%$ ethanol overnight. The infiltrated tissues were embedded into paraffin blocks. A single 3- $\mu \mathrm{m}$ section was cut from each block. Immunochemistry and the
Table I. Characteristics of prostate cancer patients.

\begin{tabular}{|c|c|}
\hline Items & $\mathrm{N}(\%)$ \\
\hline \multicolumn{2}{|l|}{ Sample type } \\
\hline Aggressive PCa & $131(48.34)$ \\
\hline Primary PCa & $140(51.66)$ \\
\hline \multicolumn{2}{|l|}{ Origin } \\
\hline The First Affiliated Hospital of Chongqing & $156(57.56)$ \\
\hline Medical University & \\
\hline The Zigong No. 4 People's Hospital & $53(19.56)$ \\
\hline The Zigong No. 1 People's Hospital & $62(22.88)$ \\
\hline \multicolumn{2}{|l|}{ Age, years } \\
\hline$<70$ & $25(9.23)$ \\
\hline $70-79$ & $148(54.61)$ \\
\hline$\geq 80$ & $98(36.16)$ \\
\hline \multicolumn{2}{|l|}{ Gleason score } \\
\hline$<7$ & $88(32.47)$ \\
\hline 7 & $89(32.84)$ \\
\hline$\geq 8$ & $94(34.69)$ \\
\hline \multicolumn{2}{|l|}{ PSA level } \\
\hline$<4$ & $34(12.55)$ \\
\hline $4-9.9$ & $35(12.92)$ \\
\hline $10-19.9$ & $41(15.13)$ \\
\hline$\geq 20$ & $161(59.40)$ \\
\hline \multicolumn{2}{|l|}{ pT stage } \\
\hline$\leq \mathrm{T} 2$ & $150(55.35)$ \\
\hline $\mathrm{T} 3$ & $75(27.68)$ \\
\hline $\mathrm{T} 4$ & $46(16.97)$ \\
\hline \multicolumn{2}{|l|}{ pN stage } \\
\hline N0 & $255(94.10)$ \\
\hline $\mathrm{N} 1$ & $16(5.90)$ \\
\hline \multicolumn{2}{|l|}{ pM stage } \\
\hline M0 & $254(93.73)$ \\
\hline M1 & $17(6.27)$ \\
\hline \multicolumn{2}{|l|}{ Therapy } \\
\hline ADT & $88(32.47)$ \\
\hline PR & $183(67.53)$ \\
\hline \multicolumn{2}{|l|}{ BCR after ADT } \\
\hline No & $15(17.05)$ \\
\hline Yes & $68(77.27)$ \\
\hline Loss & $5(5.68)$ \\
\hline \multicolumn{2}{|l|}{ CSM after RP } \\
\hline No & $137(74.86)$ \\
\hline Yes & 35 (19.13) \\
\hline Loss or death for other cause & $11(6.01)$ \\
\hline
\end{tabular}

PSA, prostate-specific antigen; $\mathrm{BCR}$, biochemical recurrence; $\mathrm{ADT}$, androgen deprivation therapy; $\mathrm{RP}$, radical prostatectomy; CSM, cancer-specific morality; $\mathrm{PCa}$, prostate cancer.

assessment of immunoreactivity were performed as described previously (18). The sections were incubated with primary 

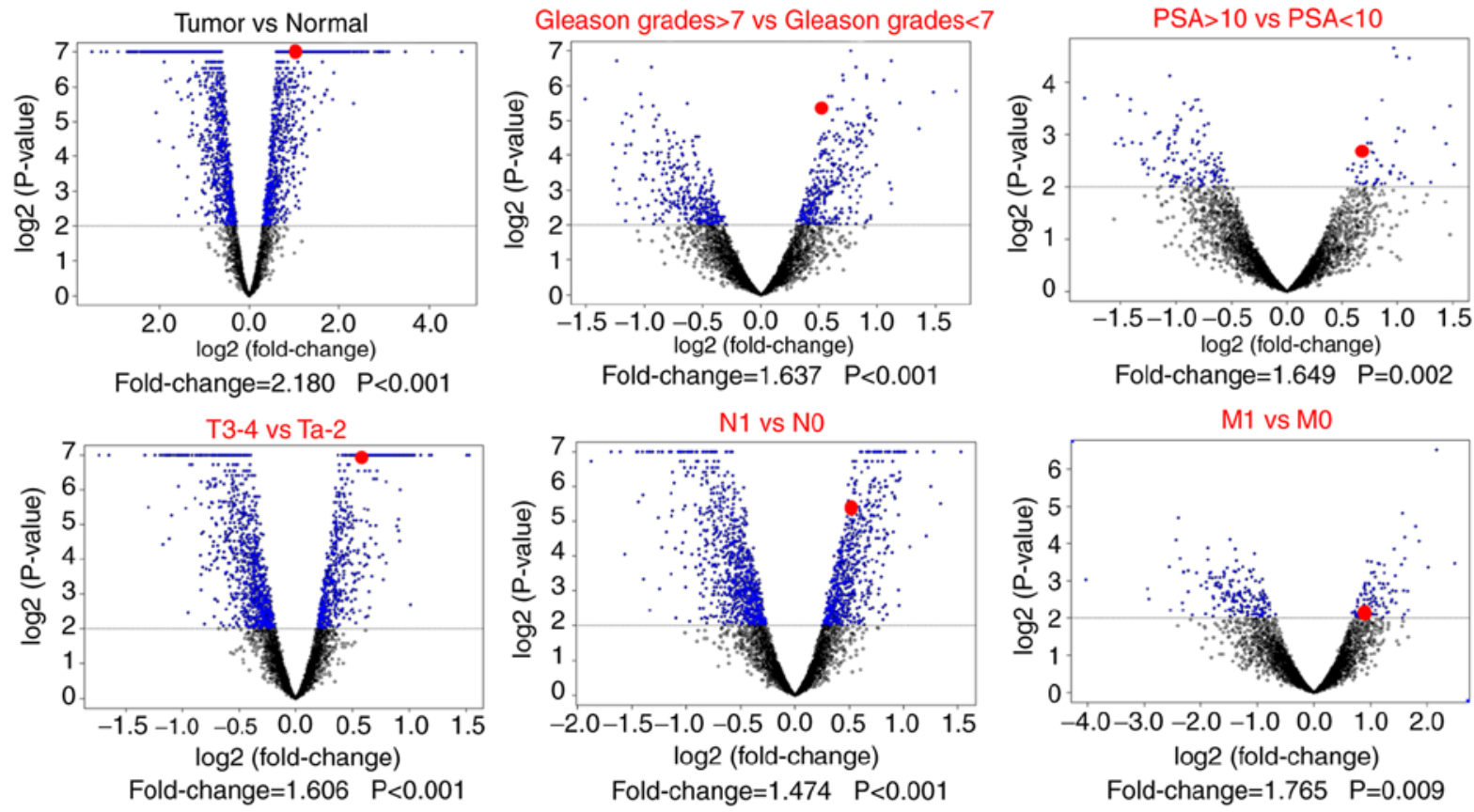

Figure 1. CIT is screened as a PCa-associated gene from the TCGA database. The fold-changes (log2 scale) of gene expression between different parameters were plotted on the $\mathrm{y}$-axis and the P-values ( $\log 2$ scale) of the FDR-corrected t-test were plotted on the $\mathrm{x}$-axis. The screening of DEGs was based on the TCGA cohort (PRAD_2015_02_24) and is indicated by blue dots $(\mathrm{P}<0.01)$. CIT is indicated by red dots $(\mathrm{P}<0.01)$. CIT, citron kinase; PCa, prostate cancer; TCGA, The Cancer Genome Atlas; DEGs, differentially expressed genes; FDR, false discovery rate; PSA, prostate specific antigen.

antibody (1:50; cat. no. YT0931; ImmunoWay Biotechnology Company) at $4^{\circ} \mathrm{C}$ overnight. CIT immunoreactivity was scored by multiplying the staining intensity by the percentage of area stained. Intensity was scored as follows: 0 (no staining), 1 (weak staining), 2 (moderate staining) and 3 (strong staining). The percentage of area stained was defined as follows: 0 (no staining), 1 (1-25\% of cells stained), 2 (26-50\% of cells stained), 3 (51-75\% of cells stained), 4 ( $>75 \%$ of cells stained). A high expression of CIT (H-CIT) was defined as 6-12, whereas a low expression of CIT (L-CIT) was defined as 0-5 (18). CIT immunohistochemical staining was scored under a light microscope independently by two experienced pathologists (LY and ZT) who were blinded to patient clinical information.

$R T-q P C R$. The isolation of total RNA and RT-qPCR were performed as described previously (19). All samples were amplified in triplicate. To calculate the expression of CIT mRNA in samples, GAPDH was used as reference gene. The following primers were used in RT-qPCR: CIT forward, 5'-ACCATAGCTGAGTTACAGGAGC-3' and reverse, 5'-GTC CCCGGTTGCTTTCTCT-3'; GAPDH forward, 5'-TGGAAG GACTCATGACCACA-3' and reverse, 5'-TTCAGCTCAGGG ATGACCTT-3'.

Statistical analyses. Statistical analyses were performed using SPSS 20.0 software (IBM Corp.) and Prism 5.0 software (GraphPad Software, Inc.). Comparison between groups was made by unpaired t-tests or Kruskal-Wallis test. The association between CIT expression and the clinicopathological parameters of patients with $\mathrm{PCa}$ was analyzed using a $\chi^{2}$ test. Follow-up outcomes were stratified to CSM for patients that received RP or BCR for patients that received ADT. The Kaplan-Meier method and a log-rank test were established to plot survival curves. Univariate and multivariate Cox regression analysis by backward selection were used to evaluate the prognostic significance of CIT for predicting BCR and CSM. The experiments were repeated 3 times and the data were presented as mean \pm standard error. $\mathrm{P}<0.05$ was considered to indicate a statistically significant difference.

\section{Results}

CIT is screened as an oncogene in PCa. A total of 3,279 DEGs were filtered from the TCGA profile when comparing normal prostate gland tissue with PCa tissue. A further screening was performed by dividing groups according to Gleason grades, serum PSA levels and tumor, node and metastasis (TNM) stages (Fig. 1). A total of 30 DEGs were identified to be significant in all of these comparisons (Table II). Significantly high expression of CIT mRNA was exhibited in PCa samples $(\mathrm{FC}=2.180 ; \mathrm{P}<0.001)$ and in patients with Gleason grades $\geq 7$ ( $\mathrm{FC}=1.637 ; \mathrm{P}<0.001)$, serum PSA levels $\geq 10 \mathrm{ng} / \mathrm{ml}$ ( $\mathrm{FC}=1.649$; $\mathrm{P}=0.002)$, T3-T4 ( $\mathrm{FC}=1.606 ; \mathrm{P}<0.001)$, positive lymph node invasion ( $\mathrm{LNI} ; \mathrm{FC}=1.474 ; \mathrm{P}<0.001$ ) and distant metastasis $(\mathrm{FC}=1.765 ; \mathrm{P}=0.009)$. The results indicate that $\mathrm{CIT}$ may be a potential $\mathrm{PCa}$-associated oncogene.

Expression of CIT is increased in PCa. The expression of CIT mRNA was increased in PCa when compared with BPH (Fig. 2A). The immunoreactivity of CIT is presented in Fig. 2B. None and low staining were detected in BPH and low-grade $\mathrm{PCa}$, whereas moderate and strong staining was detected in middle- and high-grade PCa. The staining scores of CIT were significantly increased in primary and aggressive $\mathrm{PCa}$, compared with BPH $(\mathrm{P}<0.001$; Fig. 2C). Additionally, compared with the non-HR-group, CIT expression was 
Table II. The differential expression of citron kinase mRNA in the Cancer Genome Atlas mRNA expression profiles (PRAD_2015_02_24).

\begin{tabular}{|c|c|c|c|c|c|c|c|c|c|c|c|c|}
\hline \multirow[b]{2}{*}{ Gene name } & \multicolumn{2}{|c|}{$\begin{array}{c}\text { Tumor vs. } \\
\text { normal }\end{array}$} & \multicolumn{2}{|c|}{$\begin{array}{c}\text { Gleason } \geq 7 \\
\text { vs. Gleason }<7\end{array}$} & \multicolumn{2}{|c|}{$\begin{array}{c}P S A \geq 10 \\
\text { vs. } P S A<10\end{array}$} & \multicolumn{2}{|c|}{ T3-4 vs. Ta-2 } & \multicolumn{2}{|c|}{ N1 vs. N0 } & \multicolumn{2}{|c|}{ M1 vs. M0 } \\
\hline & FC & $\mathrm{P}$ & FC & $\mathrm{P}$ & $\mathrm{FC}$ & $\mathrm{P}$ & $\mathrm{FC}$ & $\mathrm{P}$ & $\mathrm{FC}$ & $\mathrm{P}$ & $\mathrm{FC}$ & $\mathrm{P}$ \\
\hline$C I T$ & 2.18 & $<0.001$ & 1.64 & $<0.001$ & 1.65 & $<0.001$ & 1.61 & $<0.001$ & 1.47 & $<0.001$ & 1.77 & 0.010 \\
\hline STAC & 1.55 & $<0.001$ & -1.78 & $<0.001$ & -2.63 & $<0.001$ & -1.45 & $<0.001$ & -1.85 & $<0.001$ & -3.72 & $<0.001$ \\
\hline HELLS & 1.35 & $<0.001$ & 1.41 & $<0.001$ & 1.66 & $<0.001$ & 1.43 & $<0.001$ & 1.42 & $<0.001$ & 1.75 & 0.010 \\
\hline RIC3 & -1.40 & $<0.001$ & -1.38 & $<0.001$ & -1.56 & 0.010 & -1.38 & $<0.001$ & -1.42 & $<0.001$ & -2.21 & $<0.001$ \\
\hline C8orf46 & -1.54 & $<0.001$ & -1.30 & 0.010 & -1.59 & 0.010 & -1.29 & $<0.001$ & -1.32 & $<0.001$ & -1.87 & 0.010 \\
\hline$P T N$ & -1.89 & $<0.001$ & -1.75 & $<0.001$ & -2.04 & 0.010 & -1.73 & $<0.001$ & -1.89 & $<0.001$ & -2.65 & 0.010 \\
\hline NTF3 & -2.00 & $<0.001$ & -1.26 & 0.010 & -1.49 & $<0.001$ & -1.17 & $<0.001$ & -1.24 & $<0.001$ & -1.73 & $<0.001$ \\
\hline PAGE4 & -2.19 & $<0.001$ & -2.22 & $<0.001$ & -2.78 & $<0.001$ & -2.05 & $<0.001$ & -2.65 & $<0.001$ & -5.16 & $<0.001$ \\
\hline BMPER & -2.25 & $<0.001$ & -1.91 & $<0.001$ & -2.67 & $<0.001$ & -1.46 & $<0.001$ & -1.84 & $<0.001$ & -3.01 & $<0.001$ \\
\hline RSPO2 & -2.27 & $<0.001$ & -1.85 & $<0.001$ & -2.28 & $<0.001$ & -1.73 & $<0.001$ & -1.94 & $<0.001$ & -3.11 & $<0.001$ \\
\hline FXYDI & -2.31 & $<0.001$ & -1.58 & $<0.001$ & -1.97 & 0.010 & -1.36 & $<0.001$ & -1.75 & $<0.001$ & -2.55 & 0.010 \\
\hline RNF112 & -2.41 & $<0.001$ & -1.74 & $<0.001$ & -2.21 & $<0.001$ & -1.68 & $<0.001$ & -1.87 & $<0.001$ & -3.00 & $<0.001$ \\
\hline PROKI & -2.42 & $<0.001$ & -2.13 & $<0.001$ & -2.40 & $<0.001$ & -2.01 & $<0.001$ & -2.40 & $<0.001$ & -3.73 & $<0.001$ \\
\hline C20orf200 & -2.55 & $<0.001$ & -1.67 & $<0.001$ & -1.83 & $<0.001$ & -1.55 & $<0.001$ & -1.68 & $<0.001$ & -2.32 & $<0.001$ \\
\hline ANO4 & -2.82 & $<0.001$ & -1.72 & $<0.001$ & -2.23 & $<0.001$ & -1.79 & $<0.001$ & -1.99 & $<0.001$ & -2.64 & $<0.001$ \\
\hline GSTM5 & -2.96 & $<0.001$ & -1.53 & $<0.001$ & -2.01 & $<0.001$ & -1.44 & $<0.001$ & -1.75 & $<0.001$ & -2.27 & 0.010 \\
\hline$B 3 G A L T 2$ & -3.08 & $<0.001$ & -1.69 & $<0.001$ & -2.01 & $<0.001$ & -1.48 & $<0.001$ & -1.95 & $<0.001$ & -2.40 & $<0.001$ \\
\hline$A D R A 1 D$ & -3.19 & $<0.001$ & -2.05 & $<0.001$ & -1.98 & 0.010 & -1.63 & $<0.001$ & -1.97 & $<0.001$ & -2.86 & $<0.001$ \\
\hline$N D P$ & -3.30 & $<0.001$ & -1.72 & $<0.001$ & -2.04 & $<0.001$ & -1.48 & $<0.001$ & -1.71 & $<0.001$ & -2.58 & $<0.001$ \\
\hline HIF3A & -3.55 & $<0.001$ & -1.78 & $<0.001$ & -2.42 & $<0.001$ & -1.67 & $<0.001$ & -2.06 & $<0.001$ & -2.91 & $<0.001$ \\
\hline SMOC1 & -4.19 & $<0.001$ & -1.72 & $<0.001$ & -2.30 & $<0.001$ & -2.03 & $<0.001$ & -2.48 & $<0.001$ & -3.21 & $<0.001$ \\
\hline$L D B 3$ & -4.28 & $<0.001$ & -1.80 & $<0.001$ & -2.06 & 0.010 & -1.64 & $<0.001$ & -2.00 & $<0.001$ & -3.00 & $<0.001$ \\
\hline LOC572558 & -4.35 & $<0.001$ & -2.29 & $<0.001$ & -2.46 & $<0.001$ & -2.15 & $<0.001$ & -2.57 & $<0.001$ & -3.98 & $<0.001$ \\
\hline PPARGCIA & -4.42 & $<0.001$ & -1.60 & $<0.001$ & -2.08 & $<0.001$ & -1.60 & $<0.001$ & -1.98 & $<0.001$ & -2.43 & 0.010 \\
\hline HRNBP3 & -4.54 & $<0.001$ & -2.17 & $<0.001$ & -2.48 & $<0.001$ & -2.11 & $<0.001$ & -2.72 & $<0.001$ & -5.42 & $<0.001$ \\
\hline SRD5A2 & -4.57 & $<0.001$ & -1.98 & $<0.001$ & -2.17 & 0.010 & -2.18 & $<0.001$ & -2.74 & $<0.001$ & -5.26 & $<0.001$ \\
\hline COL $4 A 6$ & -4.95 & $<0.001$ & -1.84 & $<0.001$ & -2.01 & 0.010 & -1.78 & $<0.001$ & -1.98 & $<0.001$ & -3.32 & $<0.001$ \\
\hline LGR6 & -6.41 & $<0.001$ & -1.78 & $<0.001$ & -2.44 & $<0.001$ & -1.59 & $<0.001$ & -2.02 & $<0.001$ & -3.45 & $<0.001$ \\
\hline
\end{tabular}

FC, fold-change; P, P-value; PSA, prostate specific antigen.

significantly increased in the HR-group ( $\mathrm{P}<0.001$; Fig. 2D). As presented in Table III, the percentage of patients with H-CIT was significantly associated with Gleason grades $(\mathrm{P}=0.001)$, serum PSA levels $(\mathrm{P}=0.001)$, $\mathrm{T}$ stages $(\mathrm{P}<0.001)$, lymph node invasion $(\mathrm{P}=0.032)$ and metastasis $(\mathrm{P}=0.021)$. These results were consistent with those of the aforementioned bioinformatic analysis.

CIT is a risk factor for poor outcomes in patients with PCa. In IHC, the protein level of CIT expression was significantly upregulated in BCR patients $(\mathrm{P}<0.001$; Fig. 3A) and the recurrence time of patients with $\mathrm{H}$-CIT was significantly decreased compared with L-CIT ( $\mathrm{P}=0.013$; Fig. 3B). Further multivariate analysis demonstrated that the independent value of H-CIT [hazard ratio $(\mathrm{HR})=1.090-4.231 ; \mathrm{P}=0.027$ ] and LNI $(\mathrm{HR}=1.002-4.294 ; \mathrm{P}=0.049)$ was significant for $\mathrm{BCR}$ prediction (Table IV).
The results also revealed that the expression of CIT was increased in CSM patients (Fig. 3C). The Kaplan-Meier survival curve revealed that patients with H-CIT exhibited shorter survival times compared with patients with L-CIT $(\mathrm{P}<0.001$; Fig. 3D). Multivariate analysis also revealed that the independent risk factors of CSM were CIT ( $\mathrm{HR}=2.408-12.802$; $\mathrm{P}=0.000)$, Gleason grades $(\mathrm{HR}=1.148-5.068 ; \mathrm{P}=0.020)$ and T stages $(\mathrm{HR}=1.815-8.085 ; \mathrm{P}<0.001$; Table V).

\section{Discussion}

A previous study of CIT in PCa demonstrated that the loss of CIT inhibited the proliferation of LNCaP and C4-2B cells (20), however the limited number of cell types available and lack of investigation in a clinical setting restricted the study. The current study screened CIT as a potential oncogene in PCa. CIT was highly expressed in PCa samples and was associated 
A

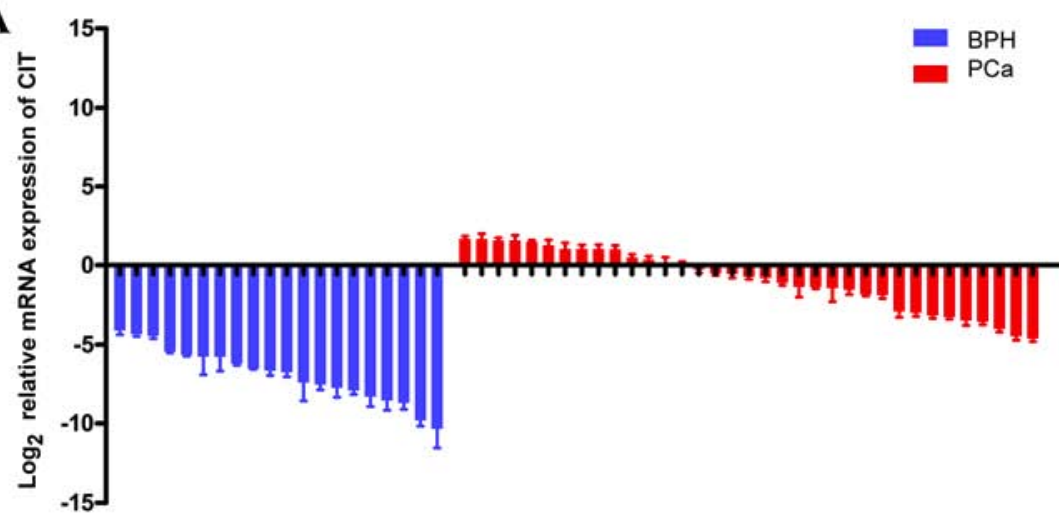

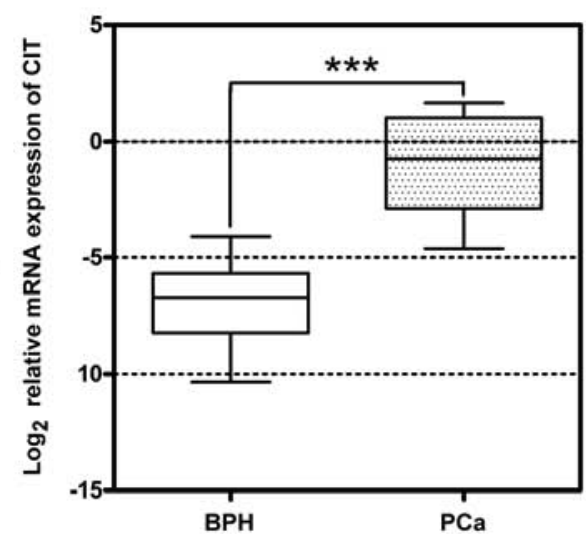

$\mathbf{B}$

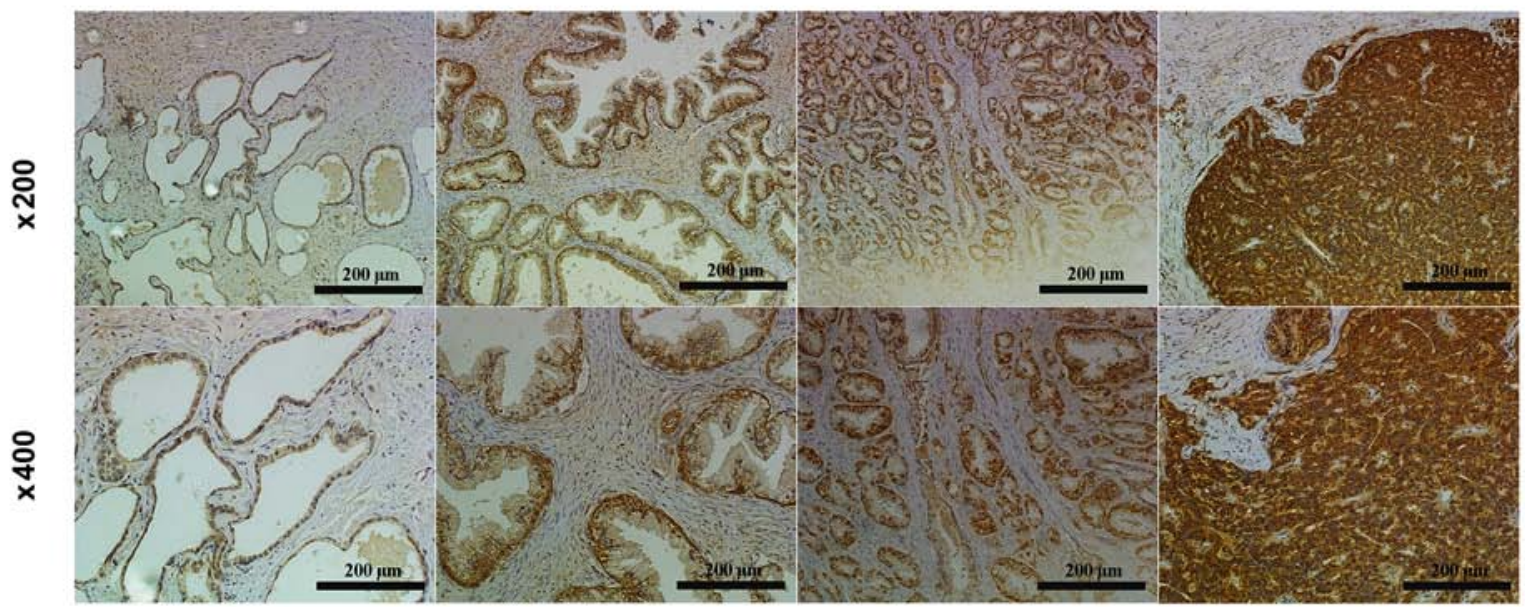

C

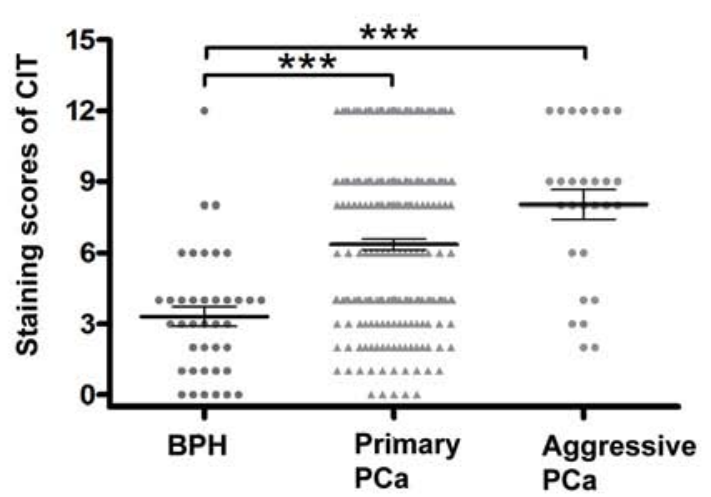

D

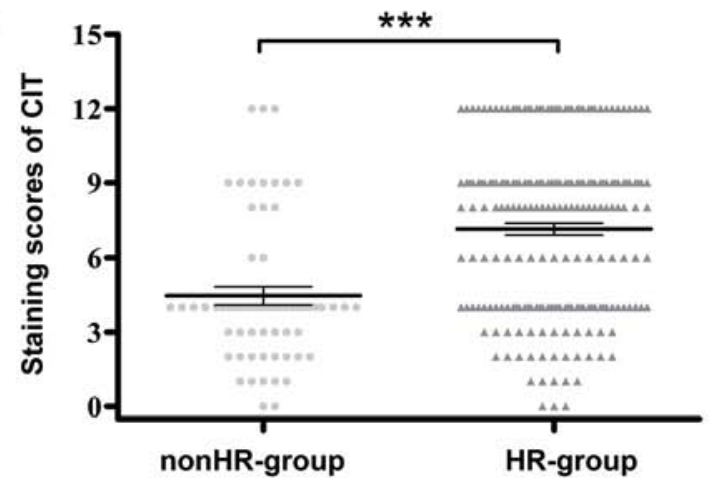

Figure 2. CIT expression is increased in PCa. (A) CIT mRNA was extracted from 35 cases of fresh PCa and 20 cases of BPH. The results of reverse transcription-quantitative PCR revealed that the mRNA expression of CIT was increased in PCa samples. Data are presented as the SEM. The overall comparison between $\mathrm{PCa}$ and $\mathrm{BPH}$ is presented in the box plot with the median result, in which the bottom and top of the boxes represent the maximum and minimum value, respectively. (B) The slides for IHC were cut from formalin fixed paraffin embedded tissue obtained from 39 cases of BPH and 271 cases of PCa. Representative images of IHC indicate CIT staining. No staining was present in BPH tissue; light staining was exhibited in low-grade PCa, moderate staining was revealed in middle-grade PCa and strong staining was indicated in high-grade PCa. Each image was captured at a respective magnification of x200 and $\mathrm{x} 400$, respectively. Compared with BPH, there was a significant increase in primary and aggressive PCa, whereas no statistically significant difference was observed between primary and aggressive PCa (C) The expression of CIT in HR-group was also higher than nonHR-group (D). Error bars represent the SEM. The data in $\mathrm{A}$ and $\mathrm{D}$ were analyzed using an unpaired t-test, and the data in $\mathrm{C}$ were analyzed using Kruskal-Wallis test ${ }^{* * *} \mathrm{P}<0.001$. CIT, citron kinase; PCa, prostate cancer; BPH, benign prostatic hyperplasia; IHC, immunohistochemistry; SEM, standard error of the mean; HR, high risk.

with Gleason scores, serum PSA levels, T stage and risk groups. Furthermore, patients with a high CIT expression were more likely to exhibit an increased BCR and CSM compared with those with a low CIT expression. Additionally, the high expression of CIT was determined to be a risk factor for BCR and CSM in patients with PCa.
Cytokinesis is the final stage of cell division, in which two daughter cells are separated (21). Resolving the midbody during the final stage of abscission serves an important role in cytokinesis (5). Failure to complete cytokinesis may lead to tetraploidy and the presence of multiple centrosomes, which has been proposed to promote tumorigenesis (22). 
Table III. Correlation between CIT and clinical parameters of prostate cancer patients.

\begin{tabular}{|c|c|c|c|c|}
\hline Parameters & No. $(\%)$ & Low CIT expression & High CIT expression & $\mathrm{P}$-value \\
\hline Gleason scores & & & & 0.001 \\
\hline$<7$ & 88 & $52(59.09)$ & $36(40.91)$ & \\
\hline$\geq 7$ & 183 & 69 (37.70) & $114(62.30)$ & \\
\hline Serum PSA (ng/ml) & & & & 0.001 \\
\hline$<10$ & 69 & $43(62.32)$ & $26(37.68)$ & \\
\hline$\geq 10$ & 202 & $78(38.61)$ & $124(61.39)$ & \\
\hline pT stage & & & & $<0.001$ \\
\hline Ta-T2 & 150 & $87(58.00)$ & $63(42.00)$ & \\
\hline T3-T4 & 121 & $34(28.10)$ & $87(71.90)$ & \\
\hline LNI & & & & 0.032 \\
\hline NO & 255 & $118(46.46)$ & $137(53.94)$ & \\
\hline $\mathrm{N} 1$ & 16 & $3(18.75)$ & $13(81.25)$ & \\
\hline Metastasis & & & & 0.021 \\
\hline M0 & 254 & $118(46.46)$ & $136(53.54)$ & \\
\hline M1 & 17 & $3(17.65)$ & $14(82.35)$ & \\
\hline
\end{tabular}

PCa, prostate cancer; BPH, benign prostatic hyperplasia; PSA, prostate-specific antigen; LNI, lymph node invasion; CIT, citron kinase.

A

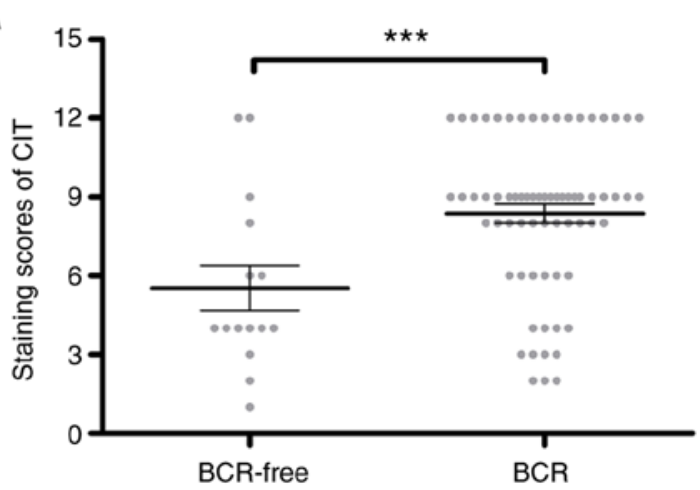

C

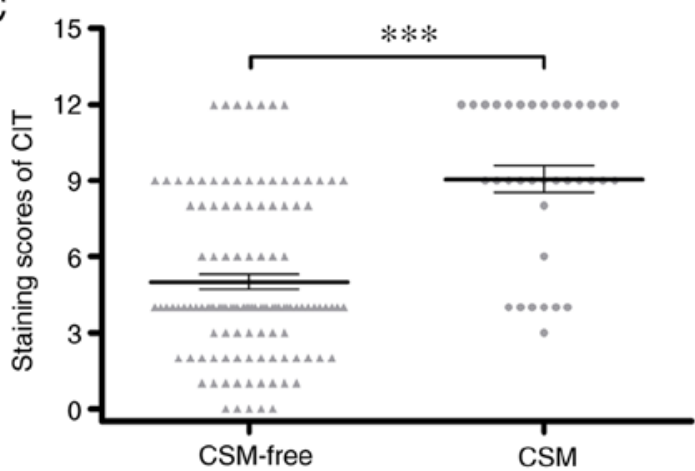

B

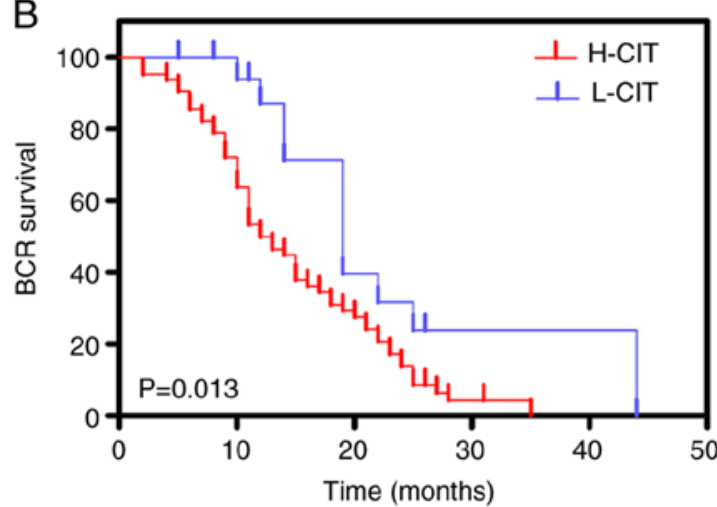

D

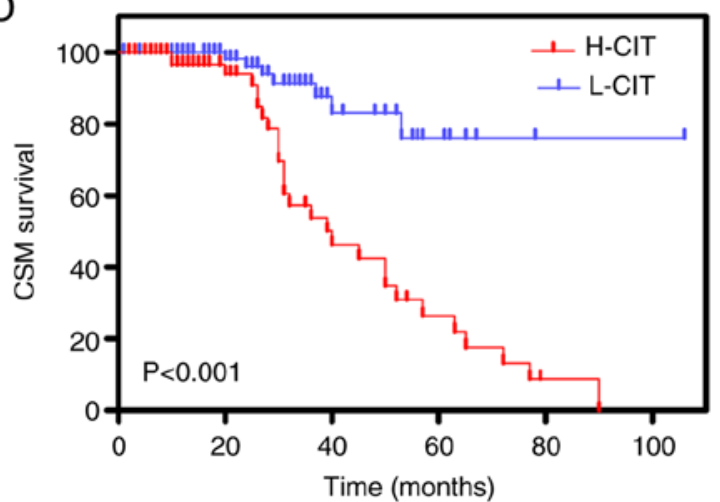

Figure 3. Prognostic value of CIT in PCa. (A and C) As revealed by the results of immunohistochemistry, the protein level of CIT was increased in BCR and CSM patients. Error bars represent the standard error of the mean. ${ }^{* * *} \mathrm{P}<0.001$. (B and D) Kaplan-Meier survival analysis revealed the survival time of $\mathrm{BCR}$ and CSM patients, with a high or low CIT expression. Data were analyzed using a log-rank test. CIT, citron kinase; PCa, prostate cancer; BCR, biochemical recurrence; CSM, cancer specific mortality.

Pihan et al (23) observed that centrosomes were structurally and numerically abnormal in the majority of patients with PCa. Furthermore, bladder cancer samples frequently contain a number of centrosomes that are significantly increased as a result of cytokinesis failure (24). CIT is specifically required during the late stages of cytokinesis for the organization 
Table IV. Univariate and Multivariate Cox regression analysis for BCR.

\begin{tabular}{|c|c|c|c|c|}
\hline \multirow[b]{2}{*}{ Variables } & \multicolumn{2}{|c|}{ Univariate } & \multicolumn{2}{|c|}{ Multivariate } \\
\hline & Hazard ratio $(95 \% \mathrm{CI})$ & P-value & Hazard ratio $(95 \% \mathrm{CI})$ & P-value \\
\hline CIT (low vs. high) & $2.231(1.137-4.377)$ & 0.020 & $2.147(1.090-4.231)$ & 0.027 \\
\hline Gleason score (<8 vs. $\geq 8)$ & $2.309(1.148-4.644)$ & 0.019 & $1.561(0.663-3.676)$ & 0.404 \\
\hline Serum PSA level ( $<10 \mathrm{vs.} \geq 10 \mathrm{ng} / \mathrm{ml})$ & $2.634(1.124-6.171)$ & 0.026 & $2.238(0.949-5.277)$ & 0.066 \\
\hline T stage (Ta-2 vs. T3-4) & $1.021(0.614-1.699)$ & 0.935 & $1.034(0.601-1.782)$ & 0.903 \\
\hline LNI (N0 vs. N1) & $2.181(1.060-4.489)$ & 0.034 & $2.074(1.002-4.294)$ & 0.049 \\
\hline Metastasis (M0 vs. M1) & $1.225(0.623-2.409)$ & 0.556 & $0.515(0.237-1.118)$ & 0.094 \\
\hline
\end{tabular}

CIT, citron kinase; PSA, prostate-specific antigen; BCR, biochemical recurrence; LNI, lymph node invasion.

Table V. Univariate and multivariate Cox regression analysis for cancer-specific morality.

\begin{tabular}{|c|c|c|c|c|}
\hline \multirow[b]{2}{*}{ Variables } & \multicolumn{2}{|c|}{ Univariate } & \multicolumn{2}{|c|}{ Multivariate } \\
\hline & Hazard ratio $(95 \% \mathrm{CI})$ & P-value & Hazard ratio $(95 \% \mathrm{CI})$ & P-value \\
\hline CIT (low vs. high) & $5.316(2.314-12.213)$ & $<0.001$ & $5.553(2.408-12.802)$ & $<0.001$ \\
\hline Gleason score $(<8$ vs. $\geq 8)$ & $1.764(0.875-3.556)$ & 0.108 & $2.412(1.148-5.068)$ & 0.020 \\
\hline Serum PSA, ng/ml (<10 vs. $\geq 10)$ & $1.452(0.628-3.355)$ & 0.383 & $0.869(0.341-2.173)$ & 0.751 \\
\hline T stage (Ta-2 vs. T3-4) & $2.977(1.504-5.895)$ & 0.002 & $3.831(1.815-8.085)$ & 0.000 \\
\hline LNI (N0 vs. N1) & $4.584(1.570-13.384)$ & 0.005 & $0.684(0.181-2.586)$ & 0.576 \\
\hline Metastasis (M0 vs. N0) & $3.032(1.570-13.384)$ & 0.134 & $1.134(0.288-5.645)$ & 0.878 \\
\hline
\end{tabular}

CIT, citron kinase; PSA, prostate-specific antigen; LNI, lymph node invasion; CI, confidence interval.

and function of the midbody $(7,25)$. The overexpression of CIT kinase-active mutants causes the dysregulation of cytokinesis, which results in the production of multinucleate cells (26). Therefore, the disrupted function of CIT may contribute to cytokinesis failure, leading to the progression of cancer. Madhavan et al (27) revealed that the activation of the CIT/kinesin family member kinesin like protein KIF14 (KIF14) axis, where CIT localizes to the central spindle via the kinesin-3 motor, KIF14, is involved in the carcinogenesis of retinoblastoma.

Various kinases have been demonstrated to be intimately involved in processes and to contribute to tumor cell proliferation and survival (28). Certain kinases are considered to be oncogenic due to their transforming capacity, including BRAF in colon carcinoma and ALK in neuroblastoma $(29,30)$. In addition, Rho-associated protein kinase serves an essential role in the metastasis and proliferation of breast cancer and hepatocellular carcinoma $(31,32)$. The knockdown of CIT directly inhibits the proliferation of breast cancer and hepatocellular carcinoma cells $(33,34)$. Since a previous study determined that CIT is an essential kinase that targets Rho-associated kinases (including ROCK and ROK) (27), it seems likely that CIT serves an important role in these cancers by interacting with Rho signaling. Previous studies have also revealed that Rho signaling factors are involved in the invasion of
PCa cells $(35,36)$, such that CIT may also participate in the regulation of Rho signaling, which serves a key role in the progression of $\mathrm{PCa}$.

Currently, the main clinical signatures of patients with $\mathrm{PCa}$ include TNM stage PSA levels and Gleason scores (37). The results of the current study revealed that a high expression of CIT was positively associated to a high T stage, serum PSA level and Gleason score. Furthermore, CIT was determined to be an independent predictor of BCR and CSM. These data indicated that CIT may serve as a potential marker of $\mathrm{PCa}$ and may compensate for these clinical signatures. Currently, ADT is one of the primary methods of treatment for patients with PCa (38). However, certain patients that receive ADT will still advance to castration-resistant $\mathrm{PCa}$ and suffer from a poor prognosis (39). Although recent studies have determined that the glucocorticoid receptor can be targeted to improve anti-androgen therapy $(40,41)$, new targets in the process of castration resistance should be explored. In the current study, patients with a high CIT expression exhibited shorter PSA recurrence time, which implies that CIT may serve a role in androgen-resistant PCa.

However, the number of PCa samples was limited in the current study and the mechanism of CIT in PCa also needs to be further elucidated. More patient samples should therefore be utilized in further study and the interaction between CIT and the Rho pathway should be determined in PCa cell lines. 
In conclusion, the results of the current long-term retrospective study indicated that CIT is an independent indicator of CSM and BCR. CIT may therefore be a potential biomarker of $\mathrm{PCa}$ in the future. Although further study is required to assess the function and mechanism of CIT in PCa, it may still serve as a biomarker to improve the survival of patients with PCa.

\section{Acknowledgements}

The authors would like to thank Professor Fangzhou Song (Department of Biochemistry \& Molecular Biology, Molecular Medicine \& Cancer Research Center, Chongqing Medical University, Chongqing, PR China) and Professor Xiaoni Zhong (Department of Health Statistics and Information Management, School of Public Health and Management, Chongqing Medical University, Chongqing, China.) for helpful suggestions. Thanks to Dr. Yutao Zhang (Department of Pathology, Zigong First People's Hospital) and Dr. Yu Li (Department of Pathology, the First Affiliated Hospital of Chongqing Medical University) for the supports of pathological information and immunohistochemical assessment.

\section{Funding}

Funding was received from: National Natural Science Foundation of China (grant no. 30972999); Nature Science Foundation of Chongqing (grant no. Cstc2016shms-ztzx0 054 and cstc2015jcyjBX0045); the Science and technology planning project of Yuzhong District (grant no. 20150111); the Health and Family Planning Commission Foundation of Chongqing Municipal (grant no. Cstc2012gg-yyjs10043); the Health Bureau of Chongqing (grant no. 20132082) and the Chongqing Education Commission (grant no. CYS16125).

\section{Availability of data and materials}

The datasets used and/or analyzed during the present study are available from the corresponding author on reasonable request.

\section{Authors' contributions}

JD and JL analyzed the data and made major contributions to writing the manuscript. YQ, YJL and YL performed the experiments and wrote the initial draft of the manuscript. JH, WW, LM and HL analyzed the data and contributed to revising the article. DW and QY contributed to the design of the study and provided final approval of the manuscript. WJ and YLia contributed to the design of the study and assisted with writing the manuscript. All authors read and approved the final manuscript.

\section{Ethics approval and consent to participate}

The Ethics committee of the First Affiliated Hospital of Chongqing Medical University, Zigong Fourth People's Hospital and Zigong First People's Hospital approved the use of these samples for the educational purposes of this research. The consent from patients or patients' families was obtained verbally.

\section{Patient consent for publication}

Not applicable.

\section{Competing interests}

The authors declare that they have no competing interests.

\section{References}

1. Siegel RL, Miller KD and Jemal A: Cancer Statistics, 2017. CA Cancer J Clin 67: 7-30, 2017.

2. Chen W, Zheng R, Baade PD, Zhang S, Zeng H, Bray F, Jemal A, $\mathrm{Yu}$ XQ and He J: Cancer statistics in China, 2015. CA Cancer J Clin 66: 115-132, 2016.

3. Pokorny MR, de Rooij M, Duncan E, Schröder FH, Parkinson R, Barentsz JO and Thompson LC: Prospective study of diagnostic accuracy comparing prostate cancer detection by trans rectal ultrasound-guided biopsy versus magnetic resonance (MR) imaging with subsequent MR-guided biopsy in men without previous prostate biopsies. Eur Urol 66: 22-29, 2014.

4. Zhang W, Vazquez L, Apperson M and Kennedy MB: Citron binds to PSD-95 at glutamatergic synapses on inhibitory neurons in the hippocampus. J Neurosci 19: 96-108, 1999.

5. Fujiwara T, Bandi M, Nitta M, Ivanova EV, Bronson RT and Pellman D: Cytokinesis failure generating tetraploids promotes tumorigenesis in p53-null cells. Nature 437: 1043-1047, 2005.

6. Ganem NJ, Storchova Z and Pellman D: Tetraploidy, aneuploidy and cancer. Curr Opin Genet Dev 17: 157-162, 2007.

7. McKenzie C, Bassi ZI, Debski J, Gottardo M, Callaini G, Dadlez M and D'Avino PP: Cross-regulation between aurora B and citron kinase controls midbody architecture in cytokinesis. Open Biol 6: 160019, 2016.

8. D'Avino PP and Capalbo L: Regulation of midbody formation and function by mitotic kinases. Semin Cell Dev Biol 53: 57-63, 2016.

9. Gai M, Camera P, Dema A, Bianchi F, Berto G, Scarpa E, Germena $G$ and Di Cunto F: Citron kinase controls abscission through RhoA and anillin. Mol Biol Cell 22: 3768-3778, 2011.

10. Yamashiro S, Totsukawa G, Yamakita Y, Sasaki Y, Madaule P, Ishizaki T, Narumiya $S$ and Matsumura F: Citron kinase, a Rho-dependent kinase, induces di-phosphorylation of regulatory light chain of myosin II. Mol Biol Cell 14: 1745-1756, 2003.

11. Zhao Y and Simon R: BRB-ArrayTools data archive for human cancer gene expression: A unique and efficient data sharing resource. Cancer Inform 6: 9-15, 2008.

12. Mottet N, Bellmunt J, Bolla M, Briers E, Cumberbatch MG, De Santis M, Fossati N, Gross T, Henry AM, Joniau S, et al: EAU-ESTRO-SIOG guidelines on prostate cancer Part 1: Screening, diagnosis, and local treatment with curative intent. Eur Urol 71: 618-629, 2017.

13. Yu L, Toriseva M, Tuomala M, Seikkula H, Elo T, Tuomela J, Kallajoki M, Mirtti T, Taimen P, Boström PJ, et al: Increased expression of fibroblast growth factor 13 in prostate cancer is associated with shortened time to biochemical recurrence after radical prostatectomy. Int J Cancer 139: 140-152, 2016.

14. Eble JN, Sauter G, Epstein JE and Sesterhenn IA: World Health Organization Classification of Tumours. Pathology and genetics of the urinary system and male genital organs. IARC Press, Lyon, 2004: 159-215, 2004.

15. Epstein JI, Allsbrook WC Jr, Amin MB and Egevad LL; ISUP Grading Committee: The 2005 International Society of Urological Pathology (ISUP) consensus conference on Gleason grading of prostatic carcinoma. Am J Surg Pathol 29: 1228-1242, 2005.

16. Goktas S, Yilmaz MI, Caglar K, Sonmez A, Kilic S and Bedir S: Prostate cancer and adiponectin. Urology 65: 1168-1172, 2005.

17. Liu J, Xiao M, Li J, Wang D, He Y, He J, Gao F, Mai L, Li Y, Liang Y, et al: Activation of UPR signaling pathway is associated with the malignant progression and poor prognosis in prostate cancer. Prostate 77: 274-281, 2017.

18. Roudier MP, Winters BR, Coleman I, Lam HM, Zhang X, Coleman R, Chéry L, True LD, Higano CS, Montgomery B, et al: Characterizing the molecular features of ERG-Positive tumors in primary and castration resistant prostate cancer. Prostate 76: 810-822, 2016. 
19. Sheng X, Li WB, Wang DL, Chen KH, Cao JJ, Luo Z, He J, $\mathrm{Li} \mathrm{MC}$, Liu WJ and Yu C: YAP is closely correlated with castration-resistant prostate cancer, and downregulation of YAP reduces proliferation and induces apoptosis of PC-3 cells. Mol Med Rep 12: 4867-4876, 2015.

20. Whitworth H, Bhadel S, Ivey M, Conaway M, Spencer A, Hernan R, Holemon H and Gioeli D: Identification of kinases regulating prostate cancer cell growth using an RNAi phenotypic screen. PLoS One 7: e38950, 2012.

21. Glotzer M: The molecular requirements for cytokinesis. Science 307: 1735-1739, 2005.

22. Boveri T: Concerning the origin of malignant tumors by Theodor Boveri. Translated and annotated by Henry Harris. J Cell Sci 121 1-84, 2008.

23. Pihan GA, Purohit A, Wallace J, Malhotra R, Liotta L and Doxsey SJ: Centrosome defects can account for cellular and genetic changes that characterize prostate cancer progression. Cancer Res 61: 2212-2219, 2001.

24. Yamamoto Y, Eguchi S, Junpei A, Nagao K, Sakano S, Furuya T, Oga A, Kawauchi S, Sasaki K and Matsuyama H: Intercellular centrosome number is correlated with the copy number of chromosomes in bladder cancer. Cancer Genet Cytogenet 191: 38-42, 2009.

25. Bassi ZI, Audusseau M, Riparbelli MG, Callaini G and D'Avino PP: Citron kinase controls a molecular network required for midbody formation in cytokinesis. Proc Natl Acad Sci USA 110: 9782-9787, 2013.

26. Madaule P, Eda M, Watanabe N, Fujisawa K, Matsuoka T, Bito H, Ishizaki $\mathrm{T}$ and Narumiya $\mathrm{S}$ : Role of citron kinase as a target of the small GTPase Rho in cytokinesis. Nature 394: 491-494, 1998.

27. Madhavan J, Mitra M, Mallikarjuna K, Pranav O, Srinivasan R, Nagpal A, Venkatesan P and Kumaramanickavel G: KIF14 and E2F3 mRNA expression in human retinoblastoma and its phenotype association. Mol Vis 15: 235-240, 2009.

28. Zhang J, Yang PL and Gray NS: Targeting cancer with small molecule kinase inhibitors. Nat Rev Cancer 9: 28-39, 2009.

29. Garnett MJ and Marais R: Guilty as charged: B-RAF is a human oncogene. Cancer Cell 6: 313-319, 2004.

30. Mossé YP, Laudenslager M, Longo L, Cole KA, Wood A, Attiyeh EF, Laquaglia MJ, Sennett R, Lynch JE, Perri P, et al: Identification of ALK as a major familial neuroblastoma predisposition gene. Nature 455: 930-935, 2008.
31. Grise F, Bidaud A and Moreau V: Rho GTPases in hepatocellular carcinoma. Biochim Biophys Acta 1795: 137-151, 2009.

32. Tang Y, Olufemi L, Wang MT and Nie D: Role of Rho GTPases in breast cancer. Front Biosci 13: 759-776, 2008.

33. Fu Y, Huang J, Wang KS, Zhang X and Han ZG: RNA interference targeting CITRON can significantly inhibit the proliferation of hepatocellular carcinoma cells. Mol Biol Rep 38: 693-702, 2011.

34. McKenzie C and D'Avino PP: Investigating cytokinesis failure as a strategy in cancer therapy. Oncotarget 7: 87323-87341, 2016.

35. Somlyo AV, Bradshaw D, Ramos S, Murphy C, Myers CE and Somlyo AP: Rho-kinase inhibitor retards migration and in vivo dissemination of human prostate cancer cells. Biochem Biophys Res Commun 269: 652-659, 2000.

36. Wu Y, He L, Zhang L, Chen J, Yi Z, Zhang J, Liu M and Pang X: Anacardic acid (6-pentadecylsalicylic acid) inhibits tumor angiogenesis by targeting Src/FAK/Rho GTPases signaling pathway. J Pharmacol Exp Ther 339: 403-411, 2011

37. Porten SP, Whitson JM, Cowan JE, Cooperberg MR, Shinohara K, Perez N, Greene KL, Meng MV and Carroll PR: Changes in prostate cancer grade on serial biopsy in men undergoing active surveillance. J Clin Oncol 29: 2795-800, 2011

38. Sharifi N, Gulley JL and Dahut WL: Androgen deprivation therapy for prostate cancer. JAMA 294: 238-244, 2005.

39. Kirby M, Hirst C and Crawford ED: Characterising the castration-resistant prostate cancer population: A systematic review. Int J Clin Pract 65: 1180-1192, 2011.

40. Puhr M, Hoefer J, Eigentler A, Ploner C, Handle F, Schaefer G, Kroon J, Leo A, Heidegger I, Eder I, et al: The Glucocorticoid receptor is a key player for prostate cancer cell survival and a target for improved Antiandrogen therapy. Clin Cancer Res 24 927-938, 2018.

41. Arora VK, Schenkein E, Murali R, Subudhi SK, Wongvipat J, Balbas MD, Shah N, Cai L, Efstathiou E, Logothetis C, et al: Glucocorticoid receptor confers resistance to antiandrogens by bypassing androgen receptor blockade. Cell 155: 1309-1322, 2013.

This work is licensed under a Creative Commons Attribution-NonCommercial-NoDerivatives 4.0 International (CC BY-NC-ND 4.0) License. 